\title{
Modelling Theft Criminal Offence in Kwara State Using ARIMA
}

\author{
AKINYEMI, Emmanuel K, OGUNLEYE, Abiodun O, GUNSOLA, Obaseye A. Olaoye, Hakeem O \\ Dept. of Statistics, Federal School of Statistics, Nigeria \\ DOI: https://dx.doi.org/10.51244/IJRSI.2021.8410
}

\begin{abstract}
A time series modeling approach (Box-Jenkins' ARIMA model) has been used in this study to forecast theft criminal offence in Kwara state. This study is centered on Time Series Analysis of Data on theft criminal Offences in Kwara State from 2006- 2015 which is restricted to only theft criminal offences in the state.

The best model is the model with the least AIC Value which is SARIMA $(0,1,1)(2,0,0)[12]$ having its AIC Value to be 898.98. The ACF of Residual showed that nearly all the spikes are within the line of boundary and the Ljung-Box statistics showed that all p-value points are above 0.05 thereby showing the accuracy of the model is good to forecast. The histogram showed that residual for the forecast which reveal that the error term for the forecast satisfies the assumption of normality, i.e. residual of the forecast is normally distributed. It was concluded that there is no residual autocorrelation i.e. there is evidence of non-zero autocorrelations in the forecast errors at lags 1 to 21 . It recommend that Government is therefore advised to aside Security operatives engage Landlords, Household heads, market women, communities/street leaders and elders as an extended mediums of getting security information.
\end{abstract}

Key words: Forecasting, Time Series Modeling, ARIMA, Assault, Kwara.

\section{INTRODUCTION}

$\mathrm{C}$ rimes become a national or community problems when it is chronic and systematic and its coincidence, pattern and seriousness become a threat to the general wellbeing of people. There are four indicators of whether or not a country or state has crime problem. These indicators are; the extent, seriousness, pattern and the control capacity or effectiveness of crime control institutions. Based on this fact, we can boldly say "Nigeria has a crime problem"

In recent times, armed violence has taken several forms in most of the states of the North Central region of Nigeria which Kwara state is an active member. Between 2012 and 2013, armed robbers attacked banks in both share and OmuAran, headquarter of Ifelodun and irepodun Local Government Area respectively leaving scores of people dead with an unimaginable degrees of injuries to others. This eventually led to the closure of banks in Omu-Aran exposing the residents of the ancient town and its environs to danger of keeping money at home.

In December $19^{\text {th }} 2013$, Offa was thrown into pandemonium as armed bandits reportedly numbered up to 30 stuck the town and invaded four commercial banks in the town. The operation which was said to have lasted for about two hours also rendered 10 policemen, 16 civilians dead and several sustained brutal injuries with several millions of naira carted away by the hoodlums (Weekly trust newspaper, 21 ${ }^{\text {st }}$ December, 2013).

Since this incident, residents of Offa, Omu-Aran, Share have been battling with fear of another attack. The fear of attack spread to Ilorin, the state capital, as banks in Ilorin throughout December/January 2013 and 2014 respectively were rendering skeletal services to their customers in a bid to minimize their possible losses in the event of an attack. This research work which is concerned with theft is aimed to fit an appropriate time series model.

\section{LITERATURE REVIEW}

Over the years, many theories have been presented in attempts to define and explain criminal activity. Some of these have focused on individual criminals while others examine the aggregate crime within an area. Although, the public perception may be that crime is randomly distributed in space, extensive evidence now exists that it is not. In this work, we dig into varieties of articles published on crime across the globe in order to have insight and general views of how crimes affect different nations of the world.

The changing picture of crime rates and public attitudes towards crime over time is a complex relationship that may not be fully explained by univariate analysis of crime rates on people's concern for crime. Criminologists, law enforcement agencies, and researchers from many academic disciplines have noticed that the public has maintained the belief that violent crime is out of control despite the fact that crime rates have been steadily declining for years. A 2008 study confirms that despite dramatically decreased crime rates in recent years, the public continues to believe that violent crime rates are out of control (Duffy, Wake, Burrows, \& Bremner, 2008). As long as this belief persists, the public tends to blame the government for failing to properly address their beliefs about crime rates and for neglecting to meet their personal safety needs (Duffy, et al. 2008). Researchers, policy makers, and law enforcement officials in the U.S. benefit from awareness of the public's varying relationship with true crime rates. If we can better understand if and when people are making logical decisions about their concern for crime relative to crime rates, we can address how to improve instances of 
irrationality when people use competing sources of information to learn about crime.

Public perceptions of crime may be swayed by several contributing factors. Felson (2002) contributes a theory for predicting people's concern for crime and attempts to explain why concern for crime and falling crime rates do not always align. Felson's random crime fallacy argues that people believe crime is random and unpredictable, while the opposite is more likely true - that crime events are actually predictable.

CNN reports informed us that USA and UK had already started public orientation and education of their citizens on the danger of joining any terror group. It had already being made a punishable offence and a law. Research has shown that education have a strong negative relationship with crimes. Education has been shown to have a strong negative correlation with crime. Machin, Marie and Vujie (2011) estimate that $1 \%$ point fall in the proportion of males leaving school with no qualifications would reduce property crime by a roughly equivalent amount. No such effect is observed for violent crime. Machin, Marie and Vujie (2011) study youth crime in more detail, identifying strong crime reducing impacts of education (this time on both property and violent crime). If government can introduce compulsory education for all and sundry in Nigeria, we believe it is a bold step forward to saving the future and avail the future of high crime rates which is obviously visible if plans to curtail are not in place. That is, the higher the number of educated; the lower the crime rates in the societies and vice versa.

\section{METHODOLOGY}

The statistical techniques that are useful for analyzing time series data will be review in this topic. The analysis of time series is based on the assumption that successive values in the data file represent consecutive measurement taken at equally spaced intervals.

\section{SOURCE OF DATA AND METHOD OF DATA COLLECTION}

The data used for this project work was collected from Kwara State Police Command Headquarter, Kwara State. The method employed is secondary method of data collection. Secondary data is a type of data which is already made that is, it has been developed by another person and not by the researcher. The data used in this project work is a monthly data of criminal offences collected on two different criminal acts; (1) THEFT (2) ASSAULT. The sample of study is Kwara State Police Command Headquarter. The data is secondary in nature and covers a period of ten (10) years from 2006 to 2015. The data is restricted to the number of criminal offences recorded at the state command only.

\section{METHOD OF DATA ANALYSIS}

A time series is a collection of observation made sequentially at equal interval of times this is denoted by $X_{t}$, where $X_{t}$ is the observed value at time $(\mathrm{t})$. The fundamental important of time series is that the observations are taken at regular interval of time. These observations are dependent on time and the successive observations are dependent on one another. Time Series Analysis (TSA) involves the degree and pattern of dependent observation $\mathrm{X}_{\mathbf{t}}$.

\section{Auto Regressive Integrated Moving Average (ARIMA)}

The ARIMA methodology was proposed by Box (1976), and it is now a quite popular tool in economic forecasting. The basic idea is that a stationary time series can be modeled as having both an autoregressive (AR) and a moving average (MA) component Non-stationary integrated series can also be handled in the ARIMA framework, but it has to be reduced to stationary beforehand by differencing the data. The multiplicative ARIMA representation can be written as

$$
\begin{aligned}
& \Phi_{p}(L)\left(1-L^{S}\right)^{\mathrm{D}}\left(1-L^{S}\right)^{\mathrm{d}} \\
& y_{t}=\delta+\theta_{q}(L) \theta_{q} L\left(\varepsilon_{t}\right) \ldots \ldots \ldots
\end{aligned}
$$

Where $\Phi_{p}(L), \phi_{p}(L)$ and $\theta_{q}(L)$ are polynomials in the lag operator (L), $\mathrm{d}$ and $\mathrm{D}$ are the number of consecutive and seasonal differences needed to make the series stationary, $\mathrm{p}$, $\mathrm{p}, \mathrm{q}$ and $\mathrm{Q}$ are the degrees of the autoregressive and moving average polynomials and $\varepsilon_{t}$ is a normally distributed random error with zero mean and constant variance. The model is multiplicative in the sense that the; observed data result from the successive filtering of a random noise $\left(\varepsilon_{t}\right)$ through the non-seasonal filter $\left(f_{p}(L)\right)$ and then the seasonal filter $(\mathrm{FP}(\mathrm{L}))$. The model is given as;

$$
X_{t}=\sum_{i=i}^{P} \emptyset_{\mathrm{t}} X_{t}+e_{t}-\sum_{j=i}^{q} \theta_{\mathrm{t}} e_{t-j} \ldots \ldots \ldots \ldots \ldots
$$

Where $\phi_{1}, \phi_{2}, \ldots \phi_{p}, \theta_{1} \theta_{2}, \ldots, \theta_{p}$, are parameters tobe estimated, $X_{t-1}$ are the lagged values of the series, $\varepsilon_{t-1}$ and are the lagged values of the white noise process?

The modeling procedure can be divided in three parts. In the first stage, the order of differencing and the degrees of the AR arid MA polynomials are determined using both the estimated autocorrelation and partial autocorrelation functions. In the second stage, the parameters ( $f, \mathrm{~F} \mathrm{q}$ and $\mathrm{Q})$ are estimated and several tests are performed to assure that the residuals are white noise. Likelihood methods are generally used for estimation purposes, but if the model has only an AR part least squares estimation will be appropriate. Finally, in the third stage, the best most parsimonious model is used to obtain the forecasts. The likelihood function stationary model can be written as

$$
\mathrm{L}\left(\phi, \theta, \delta^{2} / y_{t}\right)=(2 \pi)^{-\mathrm{T} / 2}\left(\delta^{2}\right)^{-\mathrm{T} / 2} \exp \left[\left(-\frac{1}{2 \delta^{2}}\right) \sum e^{2}\right] . .
$$

\section{Identification of ARIMA Models}

The objective of the identification is to select a subclass of the family of ARIMA models appropriated to represent a time series. We follow a two-step procedure: first, get a stationary time series, that is, we select the parameter $\delta$ of the Box-Cox transformation and the order of integration $d$, and secondly we 
identify a set of stationary ARIMA processes to represent the stationary process, that is, we choose the orders (p, q)

Analysis

Time Plot Graph for Theft Offence

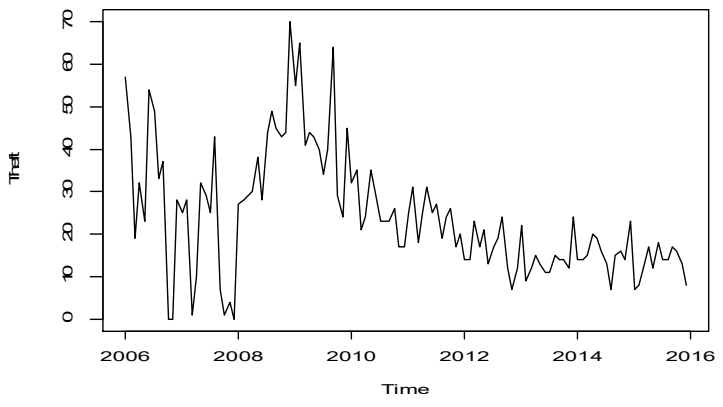

Fig 3.1: Time Plot Graph for Theft Offence

Fig 3.1 above shows the pattern of movement for the data on Theft criminal offences; and hence there will be a need to test for the stationary of the data.

\section{Unit Root Test of Stationary}

Table 3.1 DICKEY-FULLER TEST FOR THEFT OFFENCE

\begin{tabular}{l}
\hline Dickey fuller \\
\hline Augmented Dickey-Fuller Test \\
Dickey-Fuller $=-2.2204$, Lag order $=4$, sig-value $=0.485$ \\
alternative hypothesis: stationary
\end{tabular}

The appropriate hypotheses for conducting Dickey-Fuller Tests are as follows:

Null hypothesis, $\mathrm{H}_{0}$ : There is no stationarity

Versus

Alternate hypothesis, $\mathrm{H}_{1}$ : There is stationarity

By adopting the conventional Decision Rule, the decision arising from the entries in Table 3.1 is since significancevalue $(0.845)$ is greater than the $\mathrm{p}$-value; $\alpha(=0.05)$;

Hence the appropriate conclusion for the dataset is that it is not stationary at 0.05 level of significant. The consequence of this conclusion is that the condition of stationarity has not been affirmed, and therefore there is need to perform differencing.

\section{Differenced Data On Theft First Time}

Time Plot Graph Showing the Description of The Differenced Data On Theft Criminal Offence

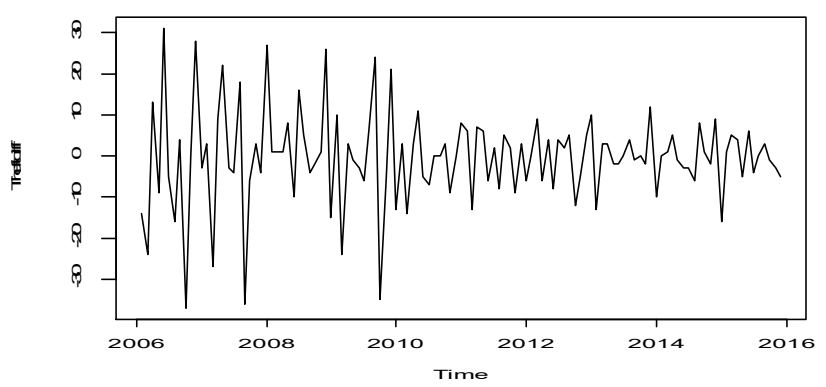

Fig 3.2 Time Plot Graph for Differenced Data on Theft Criminal Offence

Fig 3.2 shows that the pattern of movement of the differenced data and therefore test for stationary is required.

Unit Root Test of Stationary

Table 3.2 DICKEY-FULLER TEST FOR THE DIFFERENCED DATA

\begin{tabular}{l}
\hline Augmented Dickey-Fuller Test \\
\hline data: Theftdiff \\
Dickey-Fuller $=-7.0184$, Lag order $=4, \mathrm{p}$-value $=0.01$ \\
alternative hypothesis: stationary
\end{tabular}

The appropriate hypotheses for conducting Dickey-Fuller Tests are as follow:

Null hypothesis, $\mathrm{H}_{0}$ : There is no stationarity

Versus

Alternative hypothesis, $\mathrm{H}_{1}$ : There is stationarity

By adopting the conventional Decision Rule, the decision arising from the entries in Table 3.2 is since p-value (0.01) is less than the significant level, $\alpha(=0.05)$;

Hence the appropriate conclusion is the dataset is stationary at 0.05 level of significant. The consequence of this conclusion is that the condition of stationarity has been affirmed, and therefore there is no need to perform any form of differencing.

Seasonal Decomposition Chart for Theft Offence

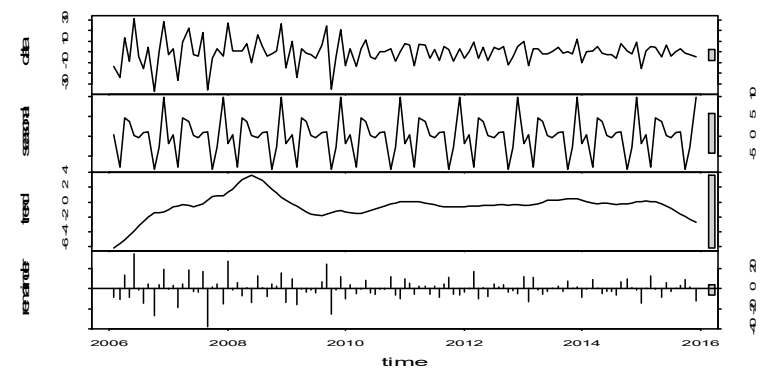

Fig 3.2 Show the seasonal decomposition graph of time series for theft offence

The above fig 3.2 chart of decomposition shows the description of the data on theft after differencing once which 
shows that the movement of the trend is not really affected by time thereby normalizing the data to be stationary. Also, it shows the seasonality of the data which reveal that there is presence of seasonal component in the series and therefore seasonal ARIMA MODEL becomes appropriate in order to correct or adjust for seasonality.

Table 3.3 TEST FOR AUTOCORRELATION AND PARTIAL AUTOCORRELATION

\begin{tabular}{|c|c|c|}
\hline Lag & ACF & PACF \\
\hline $\mathbf{1}$ & -0.29 & -0.29 \\
\hline $\mathbf{2}$ & -0.13 & -0.23 \\
\hline $\mathbf{3}$ & 0.01 & -0.12 \\
\hline $\mathbf{4}$ & -0.19 & -0.3 \\
\hline $\mathbf{5}$ & 0.17 & -0.03 \\
\hline $\mathbf{6}$ & -0.02 & -0.08 \\
\hline $\mathbf{7}$ & 0.02 & -0.01 \\
\hline $\mathbf{8}$ & 0.13 & 0.13 \\
\hline $\mathbf{9}$ & -0.06 & 0.11 \\
\hline $\mathbf{1 0}$ & -0.2 & -0.17 \\
\hline $\mathbf{1 1}$ & 0.11 & 0.01 \\
\hline $\mathbf{1 2}$ & 0.09 & 0.11 \\
\hline $\mathbf{1 3}$ & 0.1 & 0.19 \\
\hline $\mathbf{1 4}$ & -0.04 & 0.06 \\
\hline $\mathbf{1 5}$ & -0.26 & -0.18 \\
\hline $\mathbf{1 6}$ & 0.12 & -0.04 \\
\hline $\mathbf{1 7}$ & -0.04 & -0.09 \\
\hline $\mathbf{1 8}$ & -0.03 & -0.13 \\
\hline $\mathbf{1 9}$ & 0.13 & -0.06 \\
\hline $\mathbf{2 0}$ & 0.07 & 0.09 \\
\hline $\mathbf{2 1}$ & -0.12 & -0.08 \\
\hline & & \\
\hline
\end{tabular}

For the correlograms analysis, a maximum lag of 21 was used with their respective ACF's and PACF's. The corresponding ACF and PACF's values are provided in Table 3.3

\section{Correlogram Graph For Theft}
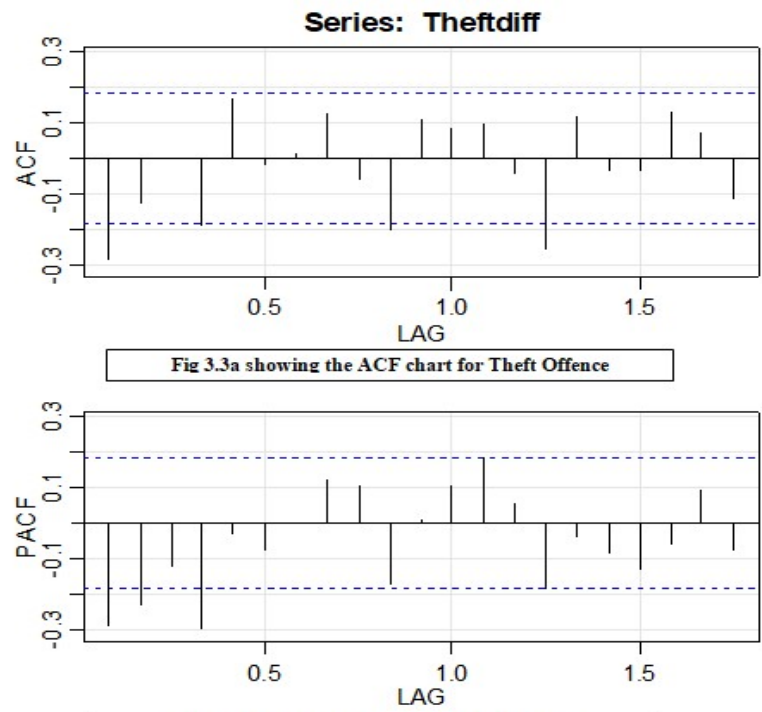

Fig 3.3b showing the PACF chart for Theft Offence
Interpretation: Fig 3.3a chart of ACF for Theft shows lag 1 to be significant negatively (-0.29), lag 59 with a small cut off from the boundary to be negatively significant (-0.06) and lag 14 is also negatively significant (0.04). Likewise, fig 3.4b of the PACF shows lag 1, lag 2 and lag 4 to be significant negatively $(-0.29,-0.23$ and -0.3$)$; therefore since the $\mathrm{ACF}$ is significant at the first lag and the PACF is significant at the first and the second lag; parsimoniously, we suggest the model SARIMA $(1,1,2)(1,1,0) 12$ with one seasonal difference for the original time series.

Table 3.4: Showing the Parsimoniously Selected Models with their respective AIC value

Selection of Model

\begin{tabular}{|c|c|c|}
\hline MODE & MODEL TYPE & AIC Value \\
\hline 1 & $\operatorname{SARIMA}(2,1,2)(2,0,0)[12]$ & 901.87 \\
\hline 2 & $\operatorname{SARIMA}(0,1,1)(2,0,0)[12]$ & 898.98 \\
\hline 3 & $\operatorname{SARIMA}(1,1,2)(2,0,0)[12]$ & 899.16 \\
\hline 4 & $\operatorname{SARIMA}(2,1,1)(1,0,0)[12]$ & 900.49 \\
\hline 5 & $\operatorname{SARIMA}(1,1,0)(2,0,0)[12]$ & 911.72 \\
\hline
\end{tabular}

Note that, having selected all these models with their respective AIC in the above table 3.5, and also using auto.arima command, it is shown that the best model is the model with the least AIC Value which is SARIMA $(0,1,1)(2,0,0)[12]$ having its AIC Value to be 898.98.

\section{Table 3.5 Best model: $\operatorname{SARIMA}(0,1,1)(2,0,0)[12]$ with zero mean}

Series: Theft

$\operatorname{SARIMA}(0,1,1)(2,0,0)[12]$ with zero mean

Coefficients:

$$
\begin{array}{ccc}
\text { mal } & \text { sar1 } & \text { sar2 } \\
-0.5905 & 0.2249 & -0.0382
\end{array}
$$

s.e. $0.08600 .1039 \quad 0.1214$

sigma $^{\wedge} 2$ estimated as 106.3: $\log$ likelihood $=-445.49$

$\mathrm{AIC}=898.98 \quad \mathrm{AICc}=899.33 \quad \mathrm{BIC}=910.1$

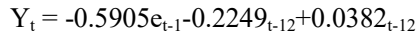

Table 3.5 SHOWING PREDICTIONS FOR JANUARY to DECEMBER, 2016

\begin{tabular}{|c|c|c|c|}
\hline Point & Forecast & Lo.95 & Hi.95 \\
\hline Jan-16 & 9.591449 & -10.6149 & 29.7978 \\
\hline Feb-16 & 9.816333 & -12.0188 & 31.65147 \\
\hline Mar-16 & 10.90256 & -12.448 & 34.25315 \\
\hline Apr-16 & 11.61113 & -13.1624 & 36.38463 \\
\hline May-16 & 10.5249 & -15.5941 & 36.64392 \\
\hline Jun-16 & 11.98879 & -15.4098 & 39.38732 \\
\hline
\end{tabular}




\begin{tabular}{|c|c|c|c|}
\hline Jul-16 & 11.20383 & -17.4171 & 39.82474 \\
\hline Aug-16 & 11.43299 & -18.3602 & 41.22616 \\
\hline Sep-16 & 11.8021 & -19.1189 & 42.72312 \\
\hline Oct-16 & 11.53902 & -20.4701 & 43.54818 \\
\hline Nov-16 & 10.94075 & -22.1208 & 44.00226 \\
\hline Dec-16 & 9.472596 & -24.6088 & 43.55397 \\
\hline
\end{tabular}

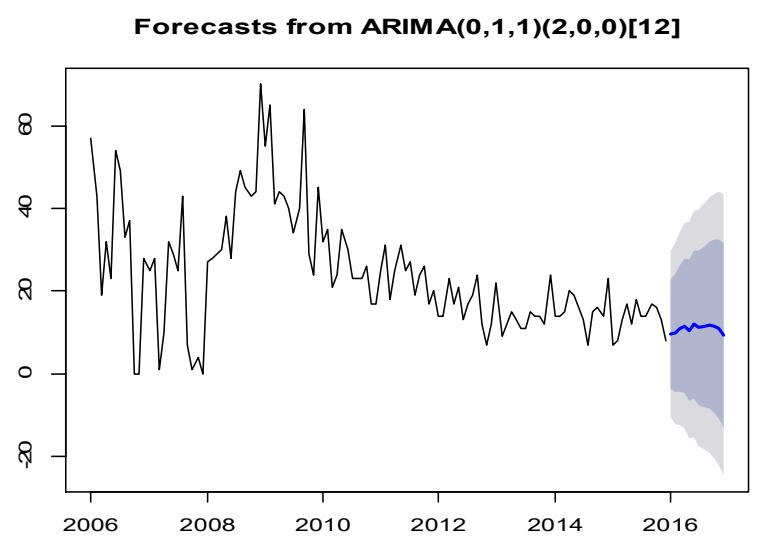

Fig 3.4 showing the forecast graph from the $\operatorname{ARIMA}(0,1,1)(2,0,0)[12]$ model

The chart in fig 3.5 above shows the forecast for Theft criminal offence for the year 2016 with the upper and lower limits of $95 \%$ and $80 \%$ respectively

\section{Diagonistic Test for the Model}

Standardized Residuals

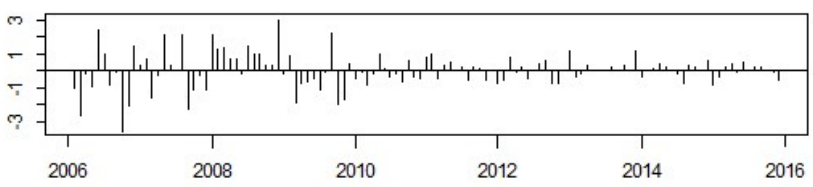

Time

Fig 3.4a: Diagnostic Test (Standardized Residual)

ACF of Residuals

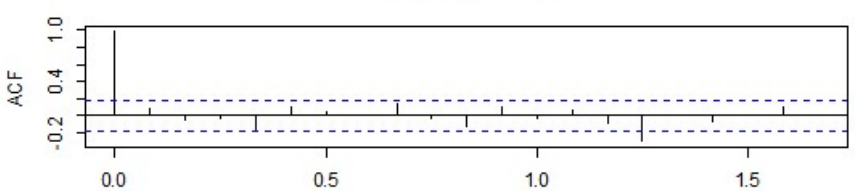

Lag

Fig 3.4b: Diagnostic Test (ACF of Residual)

$p$ values for Ljung-Box statistic

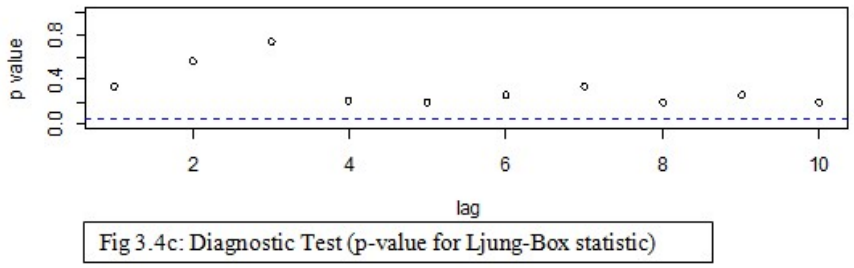

Fig 3.6a, 3.6b and 3.6c above shows that the model is independently distributed residuals, that is, the residual shows that the model is random. Also the ACF of Residual showed that nearly all the spikes are within the line of boundary and the Ljung-Box statistics showed that all p-value points are above 0.05 thereby showing the accuracy of the model is good to forecast.

Table 3.6 BOX-LJUNG TEST FOR FORECAST ERROR

Box-Ljung test
data: $\mathrm{b} \$$ residual
$\mathrm{X}$-squared $=29.099, \mathrm{df}=20, \mathrm{p}$-value $=0.08584$

The appropriate hypotheses for conducting Box-Ljung Tests are as follows:

Null hypothesis, $\mathrm{H}_{0}$ : No residual autocorrelation

Versus

Alternative hypothesis, $\mathrm{H}_{1}$ : Presence of residual autocorrelation

By adopting the conventional Decision Rule, the decision arising from the entries in Table 3.8 is not to reject Ho, since p-value $(=0.08584)$ is greater than level of significance, $\alpha$ $(=0.05)$;

Hence, the appropriate conclusion is that there is no residual autocorrelation i.e. there is evidence of non-zero autocorrelations in the forecast errors at lags 1 to 21 .

\section{Testing For the Normality of the Forecast Residual}

The test for the normality of the forecast errors is done by plotting the time plot for the forecast errors and check whether they meet the assumption of normality.

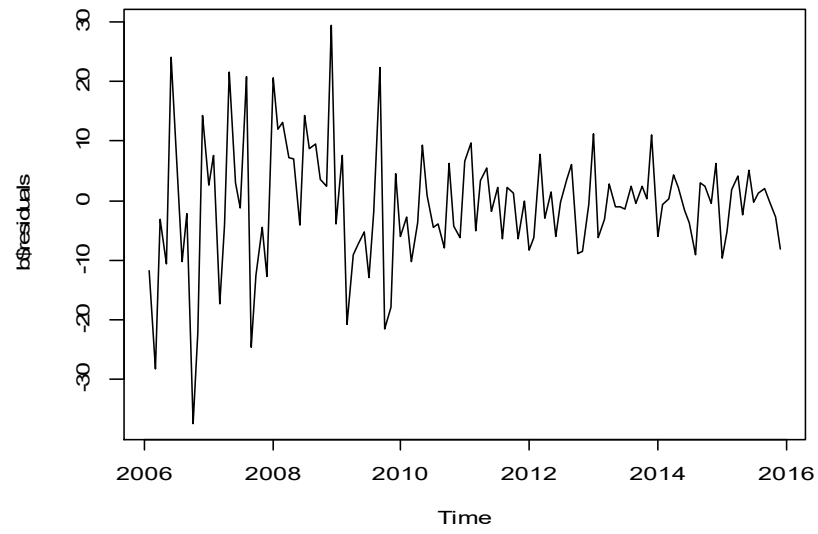

Fig 3.5 showing the plot for forecast error to check if assumption of normality is satisfied 
The time plot of the in-sample forecast errors in fig 3.7 shows that the variance of the forecast errors seems to be roughly constant over time (though perhaps there is slightly higher variance for the first half of the time series). Therefore, it is plausible that the forecast errors are normally distributed with mean zero and constant variance. Since successive forecast errors do not seem to be correlated, and the forecast errors seem to be normally distributed with mean zero and constant variance, the $\operatorname{SARIMA}(0,1,1)(2,0,0) 12$ does seem to provide an adequate predictive model for the monthly record of Theft criminal offence in Kwara State.

\section{Histogram of forecasterrors}

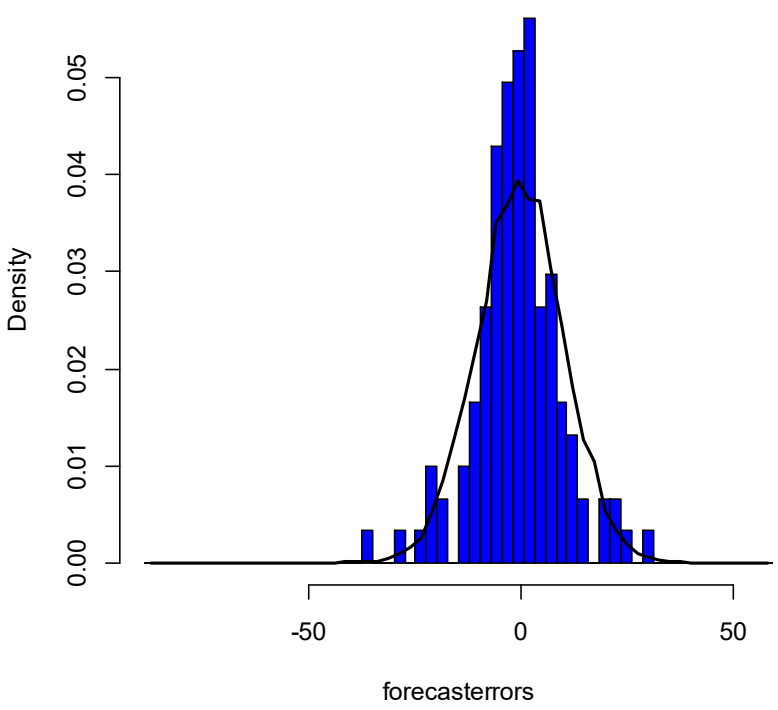

Fig 3.6: Histogram of forecast errors

The histogram in fig 3.8 above shows the residual for the forecast which reveal that the error term for the forecast satisfy the assumption of normality, i.e. residual of the forecast is normally distributed.

\section{DISCUSSION OF RESULTS}

The summary of this study is that after plotting the time plots against time ( $t$ ), Theft exhibited a non-stationarity of which we differenced so as to make it stationary which was achieved after the first differencing; likewise Assault exhibited a constant mean and variance, also the test for the seasonality showed there was seasonality present in the data's' (Assault). The ACF table for Assault shows lag 1 to lag 12 appear to differ significantly from zero (they lay outside the $95 \%$ confidence bound), and they are positive. This indicates that some months has an above average criminal offence on assault; given MA (0). Likewise, the PACF shows lag 1 to be significant positively thereby showing an AR (1); parsimoniously, suggested an ARMA $(1,0,0)$. Then a test for the adequacy of the fitted model was carried out using the Ljung-Box test which confirms the adequacy of the model. A forecast for 12 months was carried out. The model developed was also used in forecasting for 12 months starting from January 2016-December 2016, 95\% confidence interval forecast and the time plot of the forecasted data depicts a parallel movement with time.

\section{CONCLUSION}

Based on the analysis carried out, Kwara State may likely experience decrease in crime rates after which the occurrence will continue to follow the historic pattern. In essence, Kwara state is moderately save but a critical examination of the forecast ignites fear of victimization if government and security stakeholders do not intensify efforts and map out strategies of bringing the prediction under control.

\section{RECOMMENDATIONS}

The ARIMA models are recommended for forecasting Crime rate in Kwara state whilst but the following precaution measures should be taken into consideration in order to prevent wrong application of model which in turn may lead to spurious and misleading forecasting values into the future: The models should not be used to forecast long time ahead (preferably a maximum of 12 months). This is because long time periods could lead to arbitrary large forecasts values.

\section{REFERENCES}

[1] Alexandra Vaughn; Columbia University QMSS 5999 Thesis, Spring 2012; Crime Rate and Concern for Time Series Analysis.

[2] Becker, G. (1968); Crime and punishment: An economic approach. Journal of Political Economy 76, 169-217.

[3] Cantor, D. and K. C. Land (2001); Unemployment and crime rate fluctuations: A comment on Greenberg. Journal of Quantitative Criminology 17 (4), 329-342.

[4] Chatfield, C. (2004); The Analysis of Time Series, Chapman \& Hall.

[5] Commandeur, J. J. F. and S. J. Koopman (2007); An Introduction to State Space Time Series Analysis. Oxford: Oxford University Press.

[6] Gabor, T. (1978); Crime Displacement: the literature and strategies for its investigation. Crime and Justice, 6:100-7.

[7] Greenberg, D.F. (2001); Time series analysis of crime rates. Journal of Quantitative Criminology 17 (4), 291-327.3

[8] Harvey, A. C. (1989); Forecasting, Structural Time Series Models and the Kalman Filter.Cambridge: Cambridge University Press

[9] Harvey, A. C. and C. Fernandes (1989); Time series models for count or qualitative observations. Journal of Business \& Economic Statistics 7 (4), 407-417.

[10] Hird, C. and C. Ruparel (2007); Seasonality in recorded crime: Preliminary findings. Home Office Online Report (02/07). 